\title{
Mucoperiosteal Flap Necrosis after Primary Palatoplasty in Patients with Cleft Palate
}

\author{
Percy Rossell-Perry ${ }^{1}$, Omar Cotrina-Rabanal ${ }^{2}$, Luis Barrenechea-Tarazona ${ }^{3}$, \\ Roberto Vargas-Chanduvi ${ }^{3}$, Luis Paredes-Aponte ${ }^{4}$, Carolina Romero-Narvaez ${ }^{4}$ \\ ${ }^{1}$ Outreach Surgical Center Program Lima Peru, ReSurge International, Lima; ${ }^{2}$ Armonizar Foundation, Lima; ${ }^{3}$ Mission Caritas Felices, Lima; \\ ${ }^{4}$ San Bartolome Mother and Children Hospital, Lima, Peru
}

Background The prevalence of flap necrosis after palatoplasty in patients with cleft palate. The prevalence of mucoperiosteal flap necrosis after palatoplasty remains unknown, and this complication is rare. This event is highly undesirable for both the patient and the surgeon. We present here a new scale to evaluate the degree of hypoplasia of the palate and identify patients with cleft palate at high risk for the development of this complication.

Methods In this case series, a 20-year retrospective analysis (1994-2014) identified patients from our records (medical records and screening day registries) with nonsyndromic cleft palate who underwent operations at 3 centers. All of these patients underwent operations using 2-flap palatoplasty and also underwent a physical examination with photographs and documentation of the presence of palatal flap necrosis after primary palatoplasty.

Results Palatal flap necrosis was observed in 4 cases out of 1,174 palatoplasties performed at these centers. The observed prevalence of palatal flap necrosis in these groups was $0.34 \%$. Conclusions The prevalence of flap necrosis can be reduced by careful preoperative planning, and prevention is possible. The scale proposed here may help to prevent this complication; however, further studies are necessary to validate its utility.

Keywords Cleft palate / Craniofacial abnormalities / Congenital diseases
Correspondence: Percy Rossell-Perry Outreach Surgical Center, 120 Schell St, Apt 1503, Miraflores, Lima 18, Peru

Tel: $+51-1-445-2058$

Fax: $+51-1-712-3456$

E-mail: prossellperry@gmail.com

No potential conflict of interest relevant to this article was reported.

\section{INTRODUCTION}

Large defects after primary cleft palate repair are not a common complication. In such cases, the extent of functional impairment is great, which has psychological, social, and developmental consequences; therefore, the defect should be repaired [1]. The condition permits a free flow of food into the nasal cavity in a volume large enough that it may exit through the nares. In addition, the nasal secretion seeps into the mouth, producing bad taste, malodorous breath, and poor oral hygiene. Furthermore, this type of complication affects speech and resonance, with hypernasality, audible nasal escape, and weakness of pressure consonants.

Preservation of the mucoperiosteal flaps after palatoplasties guarantees the closure of the cleft and functional outcomes for speech and feeding. Mucoperiosteal flap necrosis is a rare and serious complication after palatoplasty in patients affected by cleft palates. There are few reports of this complication in the literature. A study by Diah et al. [2] in Taiwan gave a prevalence of 2 out of 64 cases (3.1\%). Another study from Nigeria observed 2 cases of flap necrosis (1\%) in patients with bilateral 
cleft palate [3]. A multivariate analysis by Deshpande et al. [4] found a low rate of flap necrosis (less than 1\%).

Since 1994, we have observed patients in Peru with severe defects after primary cleft palate repair who underwent operations by other teams. Large fistulas (mostly in patients with bilateral and isolated cleft palate) have been observed, and this was initially attributed to deficient surgical technique and/or surgeon performance. Due to the severity of this complication, an accurate prediction of flap viability is an important component of presurgical evaluation for cleft palate repair. We present here a new scale to evaluate the degree of hypoplasia of the palate and identify patients with cleft palate at high risk for the development of this complication.

The purpose of this study was to describe the prevalence of this complication and present a new scale to evaluate the degree of hypoplasia of the palatal structures and a risk score to identify patients with cleft palate at high risk for the development of this complication. This is a case series study. Possible associations with this non-desirable outcome of cleft palate repair were also evaluated for cleft anatomy and surgeon experience.

\section{METHODS}

A 20-year retrospective analysis (1994-2014) was performed

Table 1. An analysis of patients with cleft palate who underwent operations at 3 centers in Peru and developed palatal flap necrosis, 1994-2014

\begin{tabular}{|c|c|c|c|c|c|}
\hline \multirow{2}{*}{ Characteristic } & \multirow{2}{*}{$\frac{\text { Center A }}{\text { Case } 1}$} & \multicolumn{2}{|c|}{ Center B } & \multirow{2}{*}{$\frac{\text { Center C }}{\text { Case } 4}$} & \multirow{2}{*}{ Total } \\
\hline & & Case 2 & Case 3 & & \\
\hline $\mathrm{Age}^{\mathrm{a})}$ & 1 & 2 & 24 & 1 & \\
\hline \multicolumn{6}{|l|}{ Sex } \\
\hline Male & 1 & & & & 1 \\
\hline Female & & 1 & 1 & 1 & 3 \\
\hline \multicolumn{6}{|l|}{ Type of cleft } \\
\hline Veau II & & 1 & 1 & & 2 \\
\hline \multicolumn{6}{|l|}{ Veau III } \\
\hline Veau IV & 1 & & & 1 & 2 \\
\hline $\begin{array}{l}\text { TIL scale } \\
\text { Low risk } \\
\text { Moderate risk }\end{array}$ & & & & & \\
\hline High risk & 1 & 1 & 1 & 1 & 4 \\
\hline No. of surgeon's cases & 350 & 250 & 450 & 795 & \\
\hline Years of experience & 16 & 18 & 16 & 20 & \\
\hline Surgical technique & Two-flap & Two-flap & Two-flap & Two-flap & \\
\hline Prevalence & $\begin{array}{l}155 / 1 \\
(0.64)\end{array}$ & & $\begin{array}{l}5 / 2 \\
61)\end{array}$ & $\begin{array}{l}694 / 1 \\
(0.14)\end{array}$ & $\begin{array}{c}1,174 / 4 \\
(0.34)\end{array}$ \\
\hline \multicolumn{6}{|c|}{$\begin{array}{l}\text { Center A, San Bartolome Mother and Children Hospital, Lima, Peru; Center B, Mission } \\
\text { Caritas Felices, Lima, Peru; Center C, Outreach Surgical Center Program, Lima, Peru; } \\
\text { TIL, type of cleft index of the cleft palate and length of the soft palate. } \\
\text { a)Age at the time of surgery. }\end{array}$} \\
\hline
\end{tabular}

with data on surgical outcomes provided by 3 centers based in Lima, Peru: (1) San Bartolome Children's Hospital, (2) Mission Caritas Felices, and (3) the Outreach Surgical Center Program by ReSurge International. We evaluated 2 groups of patients in this study. Group A included patients who underwent operations at the above 3 centers who developed palatal flap necrosis after primary palatoplasty. A total of 1,174 nonsyndromic patients with cleft palate underwent operations at different times from 1994 to 2014 at these 3 centers in Lima, Peru. All of these patients underwent operations using 2-flap palatoplasty with intravelar veloplasty and also underwent a physical examination with photographs and documentation of the presence of palatal flap necrosis after primary palatoplasty. Group B was the group of patients with large defects (greater than the estimated congenital defect) who underwent operations by other teams and who were then evaluated during our activities at reference centers or surgical missions. We defined these cases as any secondary cleft palate case evaluated during our activities that had a defect greater than the estimated congenital cleft palate deformity. A total of 2,389 nonsyndromic patients with repaired cleft palate were evaluated at these 3 centers in Lima, Peru from 1994 to 2014. In group A, palatal flap necrosis was observed in 4 cases out of 1,174 palatoplasties performed at these different hospital centers (Table 1). The observed prevalence of palatal flap necrosis in this group was $0.34 \%$. Two of the cases involved complete bilateral cleft lip and palate and 2 involved isolated cleft palate. The demographic data of the patients are listed in Tables 1 and 2. In group B, 18 patients with large defects in their palates after primary palatoplasty were evaluated.

Patients in group B underwent operations by other teams at other sites in Peru. Their defects were greater than the congeni-

Table 2. The number of palatal necrosis cases after palatoplasty according to cleft type

\begin{tabular}{|c|c|c|c|c|}
\hline \multirow{2}{*}{ Variable } & \multirow{2}{*}{$\frac{\text { Center A }}{\text { Case } 1}$} & \multirow{2}{*}{$\frac{\text { Center B }}{\text { Case } 2 \text { Case } 3}$} & \multirow{2}{*}{$\frac{\text { Center C }}{\text { Case } 4}$} & \multirow{2}{*}{ Total } \\
\hline & & & & \\
\hline \multicolumn{5}{|l|}{ Type of cleft } \\
\hline Veau I & $16 / 0$ & & & \\
\hline Veau II & $26 / 0$ & 1 & 1 & 2 \\
\hline Veau III & $79 / 0$ & & & \\
\hline Veau IV & $34 / 1$ & & 1 & 2 \\
\hline \multicolumn{5}{|l|}{ TLL scale } \\
\hline Low risk & $45 / 0$ & & & \\
\hline Moderate risk & $81 / 0$ & & & \\
\hline High risk & $29 / 1$ & 1 & 1 & 4 \\
\hline Total & 155/1 (0.64) & $325 / 2(0.61)$ & $694 / 1(0.14)$ & $1,174 / 4(0.34)$ \\
\hline \multicolumn{5}{|c|}{$\begin{array}{l}\text { Values are presented as no. cases/flap necrosis. } \\
\text { Center A, San Bartolome Mother and Children Hospital, Lima, Peru; Center B, } \\
\text { Mission Caritas Felices, Lima, Peru; Center C, Outreach Surgical Center Program, } \\
\text { Lima, Peru; TIL, type of cleft index of the cleft palate and length of the soft palate. }\end{array}$} \\
\hline
\end{tabular}


tal cleft size (very similar to our cases) and we assume the complication was in relation to flap necrosis. Nine cases involved bilateral cleft lip and palate, 7 involved isolated cleft palate, and 2 involved unilateral cleft lip and palate. The prevalence of palatal necrosis in this group was $0.75 \%$. The demographic data of these patients are listed in Table 3. The scale presented here is based on the Type of cleft, Index of the cleft palate, and Length of the soft palate, collectively referred to as type of cleft index of the cleft palate and length of the soft palate (TIL).

\section{RESULTS}

\section{Case 1}

A 1-year-old boy presented with a history of congenital bilateral cleft lip and palate. The cleft lip was repaired at 3 months of age. The cleft palate was classified as Veau 4, Randall 3, and severe palatal index (0.45) with a high TIL risk score of 11 . The cleft palate was operated on using a 2-flap technique with intravelar veloplasty, without any intraoperative events. After 3 days, the mucoperiosteal flaps become pale and then dark and malodorous. During the next days, both flaps developed tissue necrosis at the anterior portion of the palate. Finally, a large defect was evident in the hard and soft palate with dehiscence of the nasal mucosa closure (Fig. 1). This operation was performed by a plastic surgeon with experience in nearly 350 primary cleft palate repairs.

\section{Case 2}

A 2-year-old girl presented with a history of isolated cleft palate, classified as Veau 2, Randall 4, and severe palatal index (0.52)

Table 3. An analysis of patients with cleft palate evaluated at 3 centers in Peru who had palatal flap necrosis, 1994-2014

\begin{tabular}{|c|c|c|c|c|}
\hline Characteristic & Center A & Center B & Center C & Total \\
\hline $\mathrm{Age}^{\mathrm{a})}$ & 3.3 & 2.6 & 3.5 & \\
\hline \multicolumn{5}{|l|}{ Sex } \\
\hline Male & & 2 & 2 & 4 \\
\hline Female & 3 & 4 & 7 & 14 \\
\hline \multicolumn{5}{|l|}{ Type of cleft } \\
\hline Veau II & 1 & 3 & 3 & 7 \\
\hline \multicolumn{5}{|l|}{ Veau III } \\
\hline Veau IV & 2 & 3 & 4 & 9 \\
\hline No. cases evaluated & 289 & 785 & 1315 & 2,389 \\
\hline No. flap necrosis & $3(1.03)$ & $6(0.76)$ & $9(0.68)$ & $18(0.75)$ \\
\hline \multicolumn{5}{|c|}{$\begin{array}{l}\text { Used surgical technique, surgeon's experience and TIL risk score can't be } \\
\text { estimated. } \\
\text { Center A, San Bartolome Mother and Children Hospital, Lima, Peru; Center B, } \\
\text { Mission Caritas Felices, Lima, Peru; Center C, Outreach Surgical Center Program, } \\
\text { Lima, Peru; TIL, type of cleft index of the cleft palate and length of the soft palate. } \\
\text { alMedian of estimated age at the time of surgery. }\end{array}$} \\
\hline
\end{tabular}

with a high TIL risk score of 12 . The cleft palate was operated on at 2 years of age using a 2 -flap technique with intravelar veloplasty.

During the surgery, the vascular pedicle of both flaps was difficult to identify. After 3 days, the palatal tissues become dark and malodorous, developing flap necrosis during the next days. A large defect in the hard palate developed as a consequence of the extended loss of palatal tissue (Fig. 2). This operation was performed by a plastic surgeon with experience in more than 250 primary cleft palate repairs.

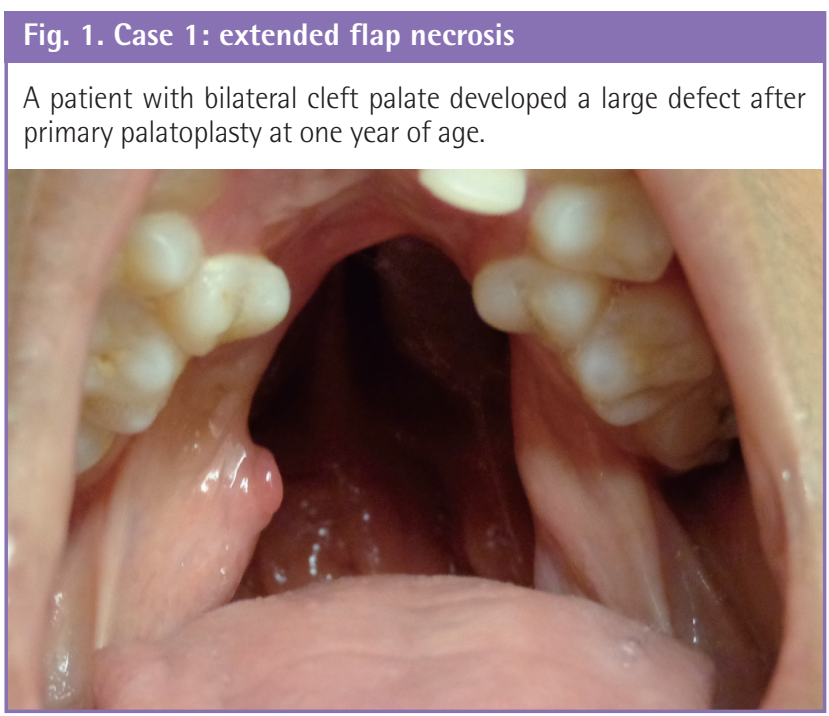

\section{Fig. 2. Case 2: hard palate necrosis}

A patient with isolated palate who had the typical aspect of palatal defect after mucoperiosteal flap necrosis. The extent of the defect is greater than the original cleft size.

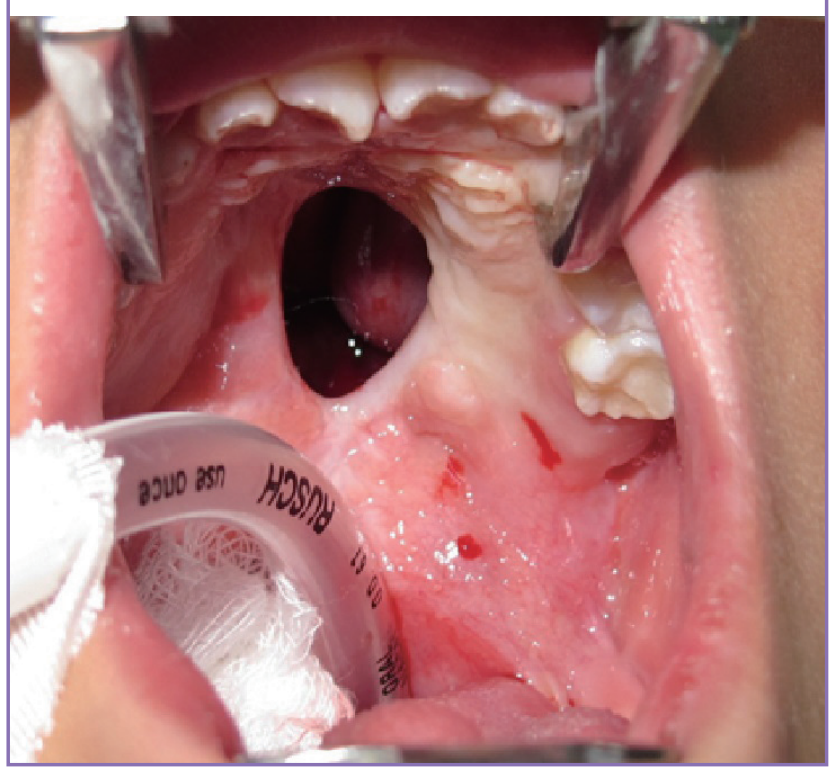




\section{Case 3}

A 24-year-old woman presented with isolated cleft palate classified as Veau 2, Randall 3, and severe palatal index (0.58) with a high TIL risk score of 11 . The cleft palate was operated on using a 2-flap technique with intravelar veloplasty. The vascular pedicles of both flaps were not identified during the surgery, and bleeding was observed when hemostasis took longer than expected. After 1 week, the patient returned and the repaired cleft palate showed necrotic tissue and wound dehiscence. The wound later healed, leaving a large defect in the hard palate. This operation was performed by a plastic surgeon with experience

Fig. 3. Case 3: preoperative view of incomplete cleft palate

A 24-year-old woman with isolated cleft palate classified as Veau 2, Randall 3, and severe palatal index (0.58) with a high TIL risk score of 9. TIL, type of cleft index of the cleft palate and length of the soft palate.

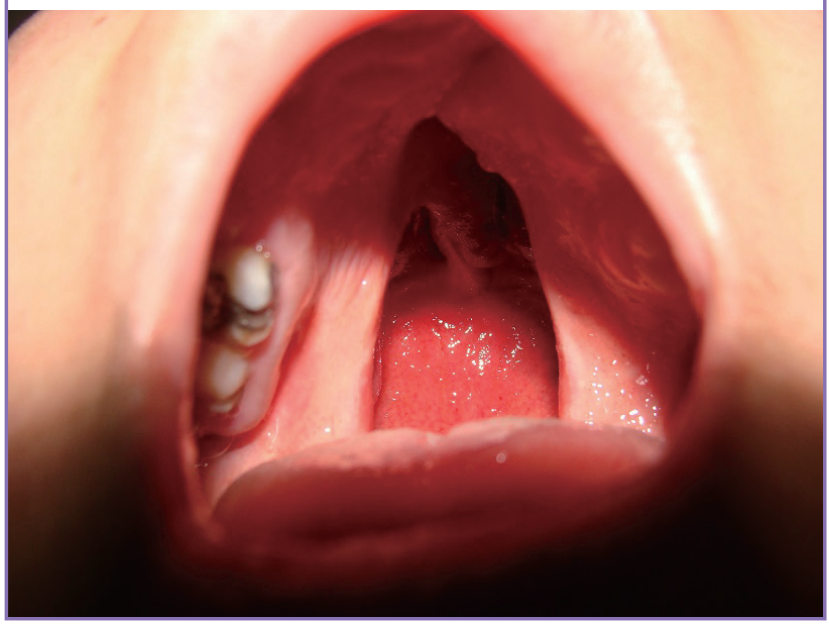

Fig. 4. Case 3: postoperative view of incomplete cleft palate case

After 1 week, the patient returned and the repaired cleft palate showed necrotic tissue in one side and dehiscence of the palate closure.

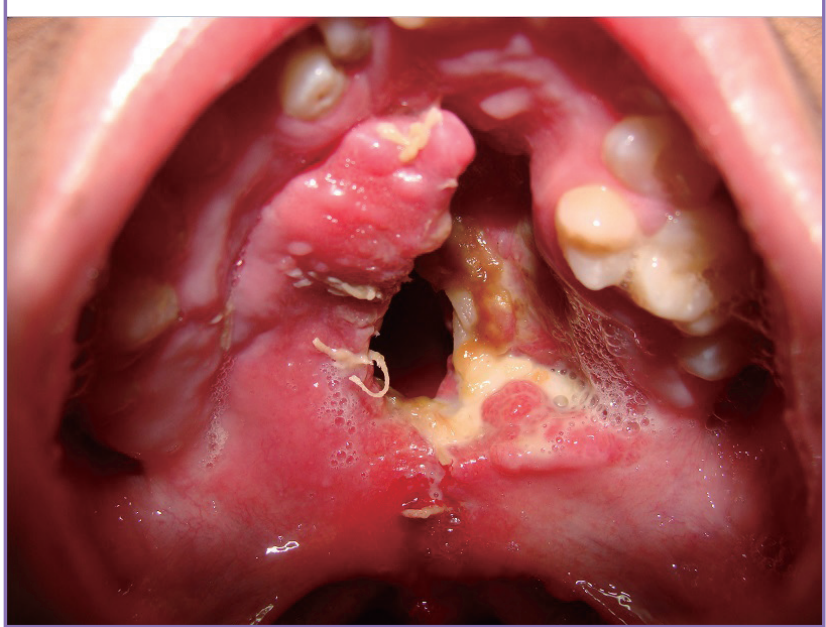

in more than 450 primary cleft palate repairs (Figs. 3, 4).

\section{Case 4}

A 1-year-old girl presented with a history of bilateral cleft lip and palate and cleft lip repair at 3 months of age. The cleft palate was classified as Veau 4, Randall 4, and severe palatal index (0.48) with a high TIL risk score of 12 . The cleft palate was operated on at 1 year of age using a 2-flap technique with intravelar veloplasty, without any intraoperative events. The pedicles of both flaps were not easily identified during the surgery, because they were very small.

The patient returned to the office at postoperative 5 days with bad odor and hyperthermia associated with flap necrosis. The

Fig. 5. Case 4: preoperative view of bilateral cleft palate

A 1-year-old girl with a history of bilateral cleft lip and palate. The cleft palate was classified as Veau 4, Randall 4, and severe palatal index (0.48) with a high TIL risk score of 12 . TIL, type of cleft index of the cleft palate and length of the soft palate.

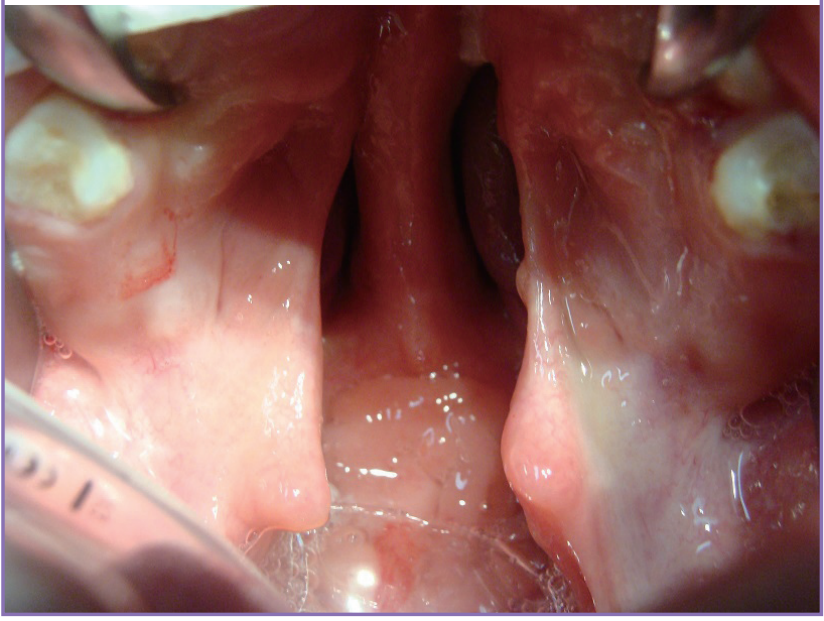

Fig. 6. Case 4: postoperative view of bilateral cleft palate

The operation site developed bilateral palatal flap necrosis and the wound healed, leaving a large defect in the hard and soft palate.

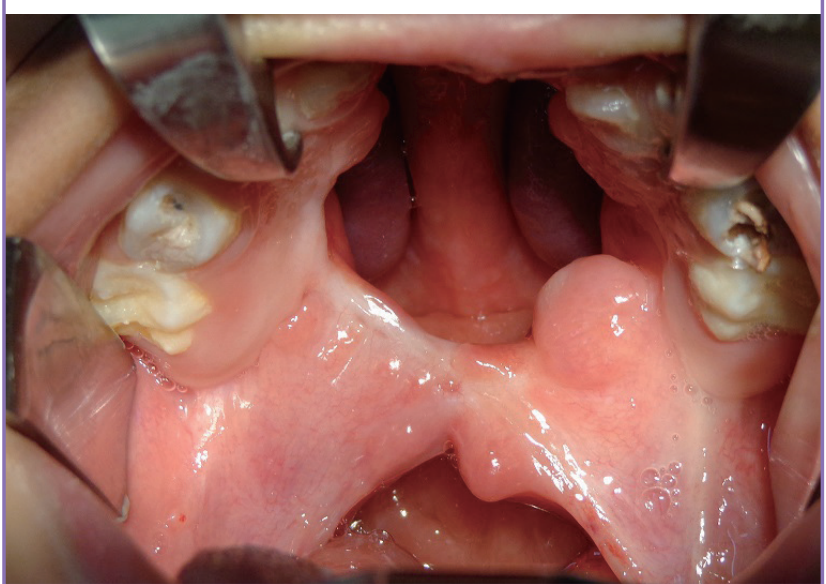


patient returned to the surgical room, the necrotic tissue was debrided, and the patient received intravenous antibiotics. Finally, the wound healed, leaving a large defect in the hard and soft palate (Figs. 5, 6). This operation was performed by an experienced surgeon with 795 palatoplasties.

\section{DISCUSSION}

The complication of flap necrosis is characterized by early signs such as change in flap color (initially pale and then dark) associated with bad odor during the first days. After 5 to 7 days, dehiscence of the surgical wound closure, loss of necrotic tissue and some bleeding appear. Then, the exposed palatal bone is resorbed, leaving a defect that is characterized by large dehiscence or a fistula (bigger than the initial congenital defect) (Figs. 1-3).

In this study, flap necrosis was observed in 4 cases operated on by plastic surgeons from the study centers with different experiences in cleft palate repair (considering years of practice and number of operated cleft palates) who used the same 2-flap surgical technique. Therefore, no association was observed between the complication and surgeon performance or surgical experience (Table 1).

Different etiologies have been described for the development of large defects after cleft palate repair, such as tension of the wound closure related to the surgeon performance and cleft width, infection, and hematoma formation; however, it appears that necrosis of the mucoperiosteal flap is the most common cause of this complication $[4,5]$.

Injury of the greater palatine arteries has been reported as a common etiology related to the necrosis of mucoperiosteal flaps; however, this event was not reported during our surgical cases. Controversy exists regarding the possible role of arterial injury, since authors such as Wardill [5] used the ligation of the vascular pedicle as a regular procedure during their operations for primary cleft palate repair without flap necrosis. Under this scenario, it seems more probably that the vascular hypoplasia associated with the tissue hypoplasia is a factor that is related to mucoperiosteal flap necrosis. This hypothesis is based on our personal observation during surgical dissection in palatoplasties and not related to any empirical evidence. This issue must be evaluated in additional studies.

In this study, we observed an association between this complication and the type of the cleft palate. The growth of the nasal septum (vomer) outstrips the growth of other skeletal and soft tissues in the midface to such an extent that it sets the pace for growth of the face and the anterior portion of the skull $[6,7]$. This situation can be clearly identified in complete unilateral cleft palate cases where the vomer is attached to the maxilla on the non-cleft side and the segment is well developed. The nonattached side is hypoplasic to different degrees. The abnormal development of the nasal septum and non-attachment to the maxilla can be observed in bilateral, isolated (included submucous-type) cleft palate, and the cleft side in unilateral cleft palate $[8,9]$. This is the explanation for the increase in reports of velopharyngeal insufficiency related to these types of cleft palate $[9,10]$.

The most severe form of hypoplasia is the absence of the vascular pedicle, and this could be considered as a possible cause of flap necrosis. In 3 of the 4 cases in which we operated, a vascular pedicle (even smaller) was found during the surgery. In 1 case the pedicle was not identified during the surgery.

As all these cases underwent operations using the same technique, a relation may be suggested between flap necrosis and the 2-flap surgical technique (Table 1).

The 2-flap technique uses 2 unipedicle flaps in which the blood supply of each depends on the greater palatine vessels. Absence, hypoplasia, and/or damage to this pedicle may affect the vascularity of these flaps. The prevalence of this complication is similar in the studied groups (less than 1\%), which may support the proposal that cleft type and the surgical technique used are related to this outcome.

The complication was observed more in women than men in the studied groups; however, this may be explained by the more common occurrence of isolated cleft palate in female patients. These hypotheses all require additional study. Based on these findings, we propose the following risk scale to evaluate cleft palate hypoplasia.

\section{The degree of cleft palate hypoplasia: a predictive scale for mucoperiosteal flap necrosis after primary palatoplasty (TIL)}

This scale (TIL) evaluates the degree of hypoplasia and is based on the following items:

a) Type of cleft. Based on the Veau classification [11] for cleft palate deformity.

1) Soft palate (score: 1 )

2) Soft and hard palate (score: 4)

3) Unilateral soft and hard palate (score: 2)

4) Bilateral soft and hard palate (score: 4)

b) Index of the cleft palate. Based on the palatal index description for cleft palate deformity $[12,13]$, the proportion between the width of the cleft (cleft severity) and the sum of the width of the 2 palatal segments (tissue deficiency) measured at the level of the hard and soft palate junction. In case of isolated soft cleft palate, the index is measured at the level of the midpoint of the height of the soft palate. 
1) Mild index: less than 0.2 (score: 1 )

2) Moderate index: 0.2 to 0.4 (score: 2 )

3) Severe index: greater than 0.4 (score: 4 )

c) Length of soft palate. Based on the Randall classification [14] for cleft palate deformity. Different studies have noted that there is a relation between the palate length and velar function $[15,16]$.

1) Uvula reaches the posterior pharyngeal wall (score: 1 )

2) Uvula reaches the posterior half of the adenoid pad (score: 2 )

3) Uvula is located at the anterior half of the adenoid pad (score: 3 )

4) Uvula is located anteriorly to the adenoid pad (score: 4)

\section{Grading scale score}

(1) Total score 3-5: low risk, (2) Total score 6-8: moderate risk, (3) Total score 9-12: high risk.

All of our cases of palatal flap necrosis occurred in patients with a high-risk score (Tables 1,2).

Palatal necrosis after cleft palate repair is a rare but significant problem. Vascular anatomical variations including hypoplasia or absence of greater palatine vessels, injury to the pedicle, cleft type, surgeon performance, and the surgical technique used may relate to this complication.

The incidence of flap necrosis can be reduced by careful preoperative planning, and prevention is possible. The TIL scale may help to prevent this complication; however, further studies are necessary to validate its utility.

\section{REFERENCES}

1. Rossell-Perry P, Arrascue HM. The nasal artery musculomucosal cutaneous flap in difficult palatal fistula closure. Craniomaxillofac Trauma Reconstr 2012;5:175-84.

2. Diah E, Lo LJ, Yun C, et al. Cleft oronasal fistula: a review of treatment results and a surgical management algorithm proposal. Chang Gung Med J 2007;30:529-37.

3. Ibrahim A, Mshelbwala P, Obiadazie A, et al. A descriptive study of clefts of the primary and secondary palate seen in a tertiary health institution in Nigeria. Niger J Surg 2013;15:
7-12.

4. Deshpande GS, Campbell A, Jagtap R, et al. Early complications after cleft palate repair: a multivariate statistical analysis of 709 patients. J Craniofac Surg 2014;25:1614-8.

5. Wardill W. The technique of operation for cleft palate. Br J Surg 1937;25:117-30.

6. Ren S, Ma L, Sun Z, et al. Relationship between palate-vomer development and maxillary growth in submucous cleft palate patients. Cleft Palate Craniofac J 2014;51:314-9.

7. Hall BK, Precious DS. Cleft lip, nose, and palate: the nasal septum as the pacemaker for midfacial growth. Oral Surg Oral Med Oral Pathol Oral Radiol 2013;115:442-7.

8. Grzonka MA, Koch KH, Koch J, et al. Malformation of the vomer in submucous cleft palate. J Craniomaxillofac Surg 2001;29:106-10.

9. Bicknell S, McFadden LR, Curran JB. Frequency of pharyngoplasty after primary repair of cleft palate. J Can Dent Assoc 2002;68:688-92.

10. Yuan N, Dorafshar AH, Follmar KE, et al. Effects of cleft width and veau type on incidence of palatal fistula and velopharyngeal insufficiency after cleft palate repair. Ann Plast Surg 2016;76:406-10.

11. Veau V. Division palatine: anatomie, chirurgie, phonétique. Paris: Masson et cie; 1931.

12. Rossell-Perry P. New diagram for cleft lip and palate description: the clock diagram. Cleft Palate Craniofac J 2009;46: 305-13.

13. Rossell-Perry P, Caceres Nano E, Gavino-Gutierrez AM. Association between palatal index and cleft palate repair outcomes in patients with complete unilateral cleft lip and palate. JAMA Facial Plast Surg 2014;16:206-10.

14. Randall P, LaRossa D, McWilliams BJ, et al. Palatal length in cleft palate as a predictor of speech outcome. Plast Reconstr Surg 2000;106:1254-9.

15. Woo AS. Velopharyngeal dysfunction. Semin Plast Surg 2012;26:170-7.

16. Guneren E, Uysal OA. The quantitative evaluation of palatal elongation after Furlow palatoplasty. J Oral Maxillofac Surg 2004;62:446-50. 